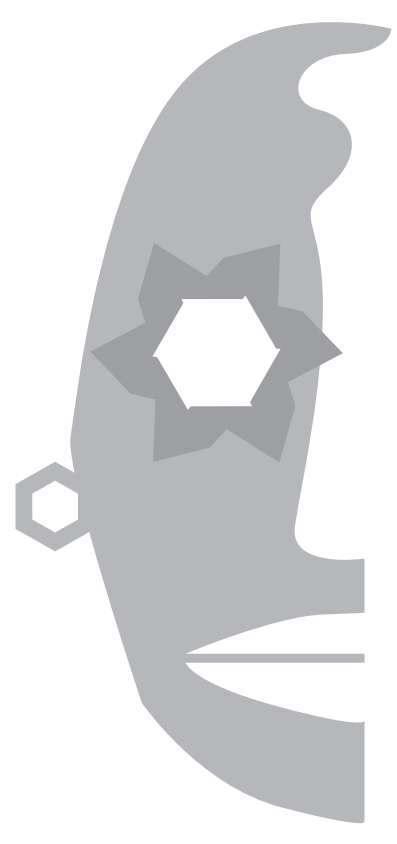

Gabriel Madriz Sojo

Universidad de Costa Rica

Ronald Sáenz Leandro

Universidad de Costa Rica

Costa Rica

\title{
Princesas rojas: la memoria histórica revisitada en el discurso cinematográfico
}

\section{RESUMEN}

Este artículo realiza un análisis político de cine para abordar algunos discursos presentes en la película costarricense Princesas rojas (2013), de la directora Laura Astorga, que permiten acceder a una mirada alternativa de la memoria histórica costarricense en cuanto a la participación de nacionales en el conflicto armado nicaragüense. A propósito, se identifica un primer discurso alternativo o de resistencia y un segundo dominante o hegemónico, de esto se concluye que los mismos configuran la disputa de dos visiones político-culturales distintas que separan las orientaciones familiares enmarcadas en un contexto ideológico de mayor envergadura.

Palabras clave: análisis político de cine; cine costarricense; discurso cinematográfico; memoria histórica; Princesas rojas.

\section{Abstract}

This article concretes a political analysis of cinema to address some speeches present in the Costa Rican film Princesas rojas (2013), by the director Laura Astorga, that allow to shape an alternative view of the Costa Rican historical memory regarding the participation of nationals in the Nicaraguan civil war. With this regard, a first alternative or resistance discourse is identified and then a second dominant or hegemonic one, from this, we conclude that they form the dispute of two different political-cultural visions that separate the familiar orientations framed in a broader ideological context.

Keywords: Political analysis of cinema; Costa Rican cinema; Cinematographic discourse; historical memory; Red Princesses. 
Este arte no es la instauración del mundo común a través de la singularidad absoluta de la forma, sino la redisposición de los objetos y de las imágenes que forman el mundo común ya dado, o la creación de situaciones adecuadas para modificar nuestra perspectiva y nuestra actitud en relación con este entorno colectivo El malestar en la estética (Rancière, 2001, p. 30)

\section{Introducción}

Para la historiadora del cine María Lourdes Cortés (2016), la película Princesas rojas (2013) de la directora costarricense Laura Astorga (San José, 1975), forma parte del corpus del nuevo cine costarricense $e^{1}$ que ha llegado a retratar la ambigua -y sempiterna- relación problemática entre Costa Rica y Nicaragua, ya sea desde lo referente a temáticas migratorias ${ }^{2}$ o bien desde otras que revisitan "la participación de los costarricenses en la guerra civil nicaragüense, ya fuera durante la euforia del triunfo o en el desencanto de la guerra frente a la contrarrevolución antisandinista" (p. 209) ${ }^{3},{ }^{4}$.

Desde la última perspectiva, Princesa rojas entroniza la interiorización familiar del conflicto bélico nicaragüense de finales de la década de los setenta e inicios de los años ochenta, dentro de la relación de pareja de dos jóvenes militantes costarricenses radicados en Nicaragua, quienes alineados ambos -en primera instancia- en torno a intereses políticos pro-sandinistas, trabajan clandestinamente desde Costa Rica para apoyar la causa armada y vulnerar las líneas de inteligencia de la "Contra"5.

El filme representa un discurso de subversión política, alineado al constructo teórico marxista y a la influencia organizacional-política y cultural de la Unión Soviética (URSS) en la región centroamericana. Recurre a una serie de elementos estéticos, tanto visuales como sonoros, que legitiman constantemente la causa de Felipe, personaje que encarna la lucha política y la ideología revolucionaria. Dichos elementos cinematográficos revelan una desarticulación discursiva en torno a Magda (pareja sentimental de Felipe) quien posteriormente abandonará la causa guerrillera -al menos desde el punto de vista logístico en la lucha armada prosandinista desde Costa Rica- por una vida de escape, pacífica y próspera en Miami.

1 Categoría acuñada por Cortés (2016) para el cine costarricense producido en el siglo XXI.

2 Como en el caso de El camino (2008), de la directora Ishtar Yasin.

3 Cortés (2016) incluye dentro de estas últimas a El compromiso del director Óscar Castillo (2011) y a El último comandante (2010), de Isabel Martínez y Vicente Ferraz.

4 Es importante precisar que una constante del cine costarricense ha sido el posicionamiento discursivo "ante el otro, que representa el peligro y que excede las fronteras nacionales", de preferencia el extranjero (Cortés, 2011, p. 7).

5 Para una profundización del conflicto bélico nicaragüense de los años ochenta, véase Zamora (1996). 
Desde este panorama, un análisis político de cine se hace pertinente en torno a la develación de estructuras discursivas que marcan la separación del "ellos" y el "nosotros". Así Von Beyme (2014) afirma que los politólogos deben ocuparse de conceptos como la memoria histórica ${ }^{7}$ y sus efectos, para entender de mejor manera la construcción de la nación, la toma de decisiones y las relaciones internacionales. A su parecer "uno no tiene que ser un constructivista radical para reconocer que la memoria histórica se construye" (Von Beyme, 2014, p. 19). Sobre esta idea, González (2012) afirma que existen prácticas estéticas que abordan el discurso histórico nacional con la finalidad de deconstruirlo en su propia práctica escritural, bien sea literaria, o bien fílmica como en este caso. Así, asumiendo la labor escritural desde dos perspectivas para el caso costarricense, es posible discernir que esta práctica estética:

por una parte, asalta el discurso histórico oficial costarricense desde una posición meramente política, al interesarse por la exclusión generalizada y sistemática que se hace en él de algunos grupos sociales; a saber, las mujeres, los indígenas, los negros, entre otros. Por otra parte, desde una perspectiva epistemológica, cuestiona y enjuicia el imaginario nacional que el discurso histórico ha construido. (González, 2012, p. 37)

En este artículo se plantea que la película de Laura Astorga pertenece a este tipo de estética y que a su vez se encuentra operacionalizada en una categoría que Iglesias (2010a, 2013) denomina como "cine de memoria histórica"; este tipo de cine, entre otras cosas, vendría a cumplir una función política crucial para la formación de prácticas de sentido desatendidas tradicionalmente por la Ciencia Política dominante. Para el mismo Iglesias (2010b), si bien el cine ocupa hoy un lugar menor en relación a otros dispositivos de la cultura audiovisual como la televisión o las series de internet, sí mantiene una "absoluta hegemonía en la ficcionalización del pasado y, en particular, en la interpretación política de ese pasado" (p. 3). En este entendido, el cine de memoria histórica funciona como mecanismo paliativo de la amnesia cultural-histórica, reinterpretando el pasado desde visiones no canónicas: a este efecto, la participación activa y militante de costarricenses en la llamada Revolución Sandinista tal y como es escenificada en la película.

6 Para ampliar sobre la propuesta del análisis político de cine aplicado al caso costarricense, véase Madriz y Sáenz (2016).

7 Entendida como "un sistema de representaciones sobre el pasado que existe en la mente de la mayoría de miembros de una sociedad; éste sistema de representaciones que está influenciado por dos factores tanto por la experiencia directa de los participantes y testigos de los eventos pasados como por la historia oficial, memoriales, medios de comunicación, literatura, etcétera; esta memoria histórica es selectiva en tanto únicamente almacena los eventos que más afectaron las vidas de las personas y éstos son simbólicos por naturaleza" (Nikiforov, 2017, p. 381). En este sentido, el filme como un mass-media tiene el potencial de resignificar eventos pasados, escenificando y realzando ciertos hechos y, por tanto, coadyuvando a restructurar las representaciones sobre el involucramiento costarricense en el conflicto nicaragüense de los ochenta, es decir, influir en la memoria histórica hegemónica. 
El presente análisis parte del supuesto del antagonismo como constitutivo de toda sociedad y de la imposibilidad del cierre societal, es decir, del supuesto de que en toda sociedad siempre prevalecerá el conflicto (de intereses, valores, ideas, visiones de mundo, entre otros) y que el consenso unánime es, por ende, imposible (Mouffe, 2011). Este supuesto es la clave para el análisis del largometraje desde el punto de vista estrictamente político pues, en primera instancia, centra su atención en el antagonismo que dibuja un "ellos" y un "nosotros" en disputa (Iglesias, 2013). En segunda instancia, logra identificar aquellas relaciones de poder entre los sujetos significantes representados (personajes del filme).

La representación del conflicto bélico (la "Contra" vs. el régimen sandinista) ${ }^{8}$ refleja un antagonismo evidente en el film; sin embargo, la articulación antagónica predominante de interés para el análisis en el largometraje es de carácter discursivo y por ende todos aquellos elementos (sujetos, objetos y prácticas simbólicas) representados en la película (mediante sonidos, imágenes y diálogos) que articulan narrativas o lógicas discursivas, son objetos de estudio para la concreción del análisis.

Ciertamente, y de forma transversal, en la representación fílmica se puede inferir la ambientación escénica de la disputa bélica bipolar por el control político de Nicaragua que, pasando a segundo plano, da pie a la representación dominante de un conflicto de ideas (por las ideas) o a un antagonismo respecto a dos proyectos político-culturales que en la psicología de los personajes llegan a significar marcos de referencia sobre cómo enfrentar la vida. Es por ello que, esta representación fílmica del antagonismo se realiza no desde el rodaje gráfico de la guerra ${ }^{10}$ misma, sino desde la realidad de una familia costarricense y de su desintegración o bifurcación dicotómica en torno a dos discursos distintos. La presencia de estos discursos contrapuestos en el film se refleja con la aparición de distintas formas de diagnosticar y pronosticar la realidad (de interpretar el presente y proyectar el futuro) por parte de los personajes (sujetos significantes) ${ }^{11}$; además con la identificación de sus "estrategias" (prácticas o acciones) para gestionar tanto este conflicto por las ideas como la realidad misma, es decir: el contexto y los problemas que este acarrea para cada personaje según sus intereses o motivaciones particulares.

8 Que a grandes rasgos también remite a la confrontación hegemónica mundial de la segunda mitad del s. XX entre las superpotencias mundiales: EE.UU. y la URSS.

9 En el presente trabajo se entenderá por articulación a "toda práctica que establece una relación tal entre elementos, que la identidad de éstos resulta modificada como resultado de esa práctica" (Laclau y Mouffe, 1987, p. 176). Y por discurso se entenderá "la totalidad estructurada resultante de esta práctica articulatoria" Laclau y Mouffe (1987, p. 177).

10 Para Sánchez (2011) el tópico de la guerra ha sido tratado con bastante pudor por la tradición narrativa costarricense. Aquí se confirma que este efecto también ha acarreado repercusiones para la narrativa audiovisual.

11 Particularmente los personajes con mayor protagonismo en la película: Felipe, Magda y Claudia. 


\section{El discurso cinematográfico en Princesas rojas}

Ranciére (2001) afirma -siguiendo al famoso cineasta y teórico fílmico Serguéi Eisenstein- que el cine es una cadena de imágenes que se pretende transformar en conexiones de ideas. Entonces ¿cuáles son estas conexiones de ideas que se ven expuestas en Princesas rojas? ¿Cuáles son estos discursos antagónicos que se pueden identificar en el filme?

Se propone que el antagonismo discursivo en el filme gira en torno a:

1) La tesis de la "revolución permanente" 12 y la ideología comunista.

2) El discurso de la paz y la estabilidad familiar presente en la cultura e identidad costarricense ${ }^{13}$ aunado a la idea del "sueño americano"14.

Por un lado, se identifica a Felipe, quien está dispuesto a continuar con sus operaciones clandestinas pro-sandinistas, a pesar de que significa un riesgo tanto para su familia (hijas), como para su estabilidad de pareja y para su vida. Por otro, se escenifica a Magda, quien antepone la seguridad de su familia (hijas) aunque ello implique traicionar a su esposo al colaborar con el bando contrario del conflicto bélico y romper con una relación de pareja. Estos dos personajes (sujetos) son los que, junto con una serie de objetos simbólicos, prácticas de sentido y otros sujetos, logran escenificar los dos discursos en pugna. La materialización del conflicto de discursos donde se identifica una clara oposición de estos dos personajes de referencia en la película yace en la disputa por la custodia de las niñas (Antonia y Claudia).

Ambos personajes identificados (quienes personifican los discursos antagónicos recién señalados) comparten un aspecto crucial de su diagnóstico de la realidad vivida: que el conflicto armado acarrea peligros tanto para las niñas (hijas) como para su vida (problemática experimentada) y que lo deseable es un clima de paz y estabilidad; sin embargo, interpretan el conflicto de una forma diferente. Por una parte, Felipe observa que, a pesar de que suscita peligros, este puede ganarse a su favor (en pro del régimen sandinista); y Magda entiende, por otra parte, que el conflicto

12 Tesis de Trotsky referida a "la necesidad (...) de que la revolución mantenga en todo momento su internacionalismo, es decir, que no puede quedar confinada a un solo país" (Giner, 1987, p. 577). Así, la narrativa extraída del film que encarna Felipe consiste en el mantenimiento de la confrontación revolucionaria tanto desde Nicaragua como desde Costa Rica para luego extenderse en Costa Rica. Esta idea de expansión e internacionalismo trasciende lo político-organizacional (establecer regímenes comunistas) de forma que también hay una difusión de la cultura soviética-cubana y nuevos valores (p.ej. el sacrificio, el cambio, la juventud).

13 De acuerdo con Pacheco (2013): "en la actualidad es posible afirmar que el proceso de conformación de la identidad costarricense continúa basándose en ideas nacionales imaginadas tales como la diferencia del resto de Centroamérica, la homogeneidad cultural, la ascendencia europea, la democracia, el pacifismo y la igualdad" (p. 27).

14 Según Camacho (1997) citado en Pacheco (2013) Estados Unidos paulatinamente ha desplazado a España o París como centro de identidad imaginada costarricense de tal forma que, haciendo una lectura del Área Metropolitana de San José [Costa Rica]: "Miami surge como la referencia simbólica más evidente” (p. 27). 
es sumamente inseguro para las niñas (sus hijas), además conlleva una vida errante e inestable y la condiciona a ejercer actividades que no son de su agrado.

Esta discrepancia en el diagnóstico produce una diferencia en la maniobra o acción (terapia o propuesta de solución) para gestionar la problemática vivida por ambos personajes (y sus hijas). Por un lado, Felipe, fiel a la praxis revolucionaria, entiende que la única manera de forjar una vida de paz con su familia en Costa Rica es apoyar la causa sandinista, que esta logre triunfar y que se extiendan organizaciones "pioneras” en el país para que la juventud (escenificada por las niñas) puedan consolidar en el futuro el comunismo añorado por las tesituras marxistas (pronóstico, mito sugerido o sociedad idealizada en el film). Por otro lado, Magda comprende que, para poder ejercer su trabajo de una manera segura, donde no comprometa la seguridad de sus hijas, consiste en escapar geográficamente del conflicto e irse a EE.UU. donde pueda reinventarse de forma estable y pacífica.

Ahora bien, ¿cómo se tejen estos discursos en el largometraje? ¿Cuáles objetos, sujetos y prácticas representadas se articulan en cada discurso?

\section{EI discurso alternativo o de resistencia}

El primer discurso ("revolución permanente") refleja un estricto apego a la ideología marxista, a la cultura ruso-soviética y al interés del mantenimiento del régimen sandinista en Nicaragua ("defensa de la revolución"). Desde el inicio de la película se denota una fuerte articulación de los personajes en torno a este discurso y así lo revela la integración familiar, y principalmente la estabilidad de la relación entre Felipe y Magda (ver Figura 1), quienes una vez ubicados en Costa Rica inician con las operaciones clandestinas (prácticas de sentido); entre ellas: la fabricación de pasaportes falsos para sumar costarricenses a la lucha armada.

Figura 1. Felipe y Magda se toman la mano representando una articulación

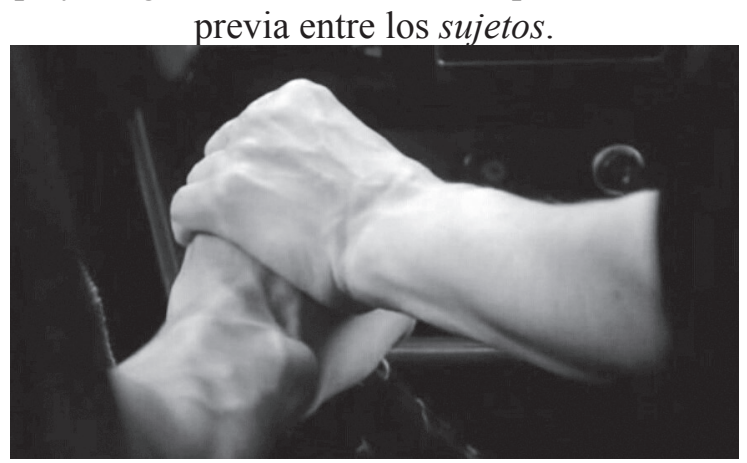

Fuente: Tomado de Astorga (2013). 
El discurso muestra un "nosotros" articulado en torno a Felipe, sus camaradas del régimen sandinista y su familia: las niñas y Magda (sujetos). La posición de los sujetos solamente se revela desde el discurso pro-revolucionario a través del significante "pioneros". Los llamados pioneros son las organizaciones juveniles comunistas presentes en Cuba que presenta prácticas similares al escultismo (Movimiento Scout). Estas se legitiman en el texto del guion cinematográfico. A continuación, se presenta un diálogo entre los actores que hace manifiesto el discurso pro-revolucionario:

(Se bajan las niñas del autobús escolar y Felipe las espera, seguidamente se abrazan).

Felipe - "Hey, quitate eso Claudia". (Un pin comunista).

Claudia - "Ah, si".

Antonia - "¿Y mami, papi?".

Felipe - “YY la escuela? ¿Cómo estuvo?”. (Evadiendo la pregunta).

Claudia - "Pá! En Costa Rica no hay pioneros ¿Entonces no puedo ir a

Cuba?".

Felipe - "Claro que no hay pioneros, pero se pueden hacer organizándose". (Claudia sonríe).

El significante "pioneros" es el predominante en el film (punto nodal), representado por los deseos de Claudia de instaurar en Costa Rica una organización de "pioneros" (organización de niños dirigida por el Partido Comunista), establecer un régimen organizacional con reglas para quienes conforman la organización y de que su hermana se pueda unir eventualmente a dicha organización (es decir, alcanzar el status de "pionera"). El punto nodal precisamente es el que ancla el conjunto de prácticas y objetos simbólicos presentes en el film, y es el significante con el que se logra afirmar que el discurso es de carácter estrictamente comunista e ideológico. El discurso se puede interpretar como la pretensión de una amplitud del comunismo (juvenil) en Costa Rica, y en general este intenta reivindicar la posibilidad (el pronóstico o la expectativa) de que en Costa Rica se pueda vivir como se vivió el comunismo en Nicaragua, sin el conflicto del que huyen los personajes (imaginario social); aunque ello implique preliminarmente arriesgar la vida (de la familia y del mismo Felipe) en encomiendas secretas pro-sandinistas. En definitiva, el objetivo compartido de Felipe y las niñas es asentar su vida en Costa Rica y vivir libremente de su pensamiento comunista y la cultura ruso-soviética.

El contenido de objetos simbólicos es vasto, así como de prácticas escenificadas que denotan el discurso una y otra vez. El objeto simbólico por excelencia lo constituyen los pines soviéticos que coleccionaba Claudia (ver Figura 2). Precisamente este objeto determina quién y en qué momento determinado personaje está articulado (o no) en torno a este discurso. En torno a este objeto es que se 
presenta una escena crucial del filme y tiene que ver con el ajetreo entre Claudia y su madre Magda (ver Figura 3); ya que esta última al ver a su madre distante de su padre y al escuchar sobre su viaje a Miami intenta, de forma simbólica, restablecer el orden familiar anterior colgándole el pin en su vestimenta; aspecto que genera gran disgusto en Magda, quien con violencia decide quitárselo, es decir, rompe simbólicamente con aquellas prácticas clandestinas que en algún momento sirvieron de orientación en su vida. Esta última escena representa una desarticulación discursiva en la cual los elementos del discurso de la "revolución permanente" se disocian (Magda como sujeto y los pines comunistas como el objeto con mayor carga simbólica del film).

Figura 2. Claudia ordena sus pines con alusiones comunistas.

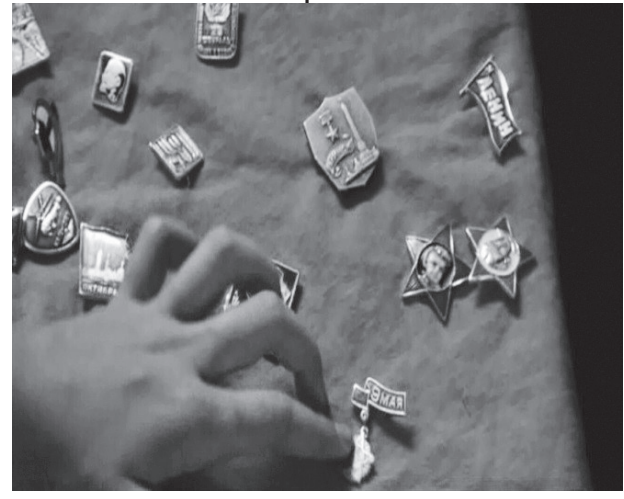

Fuente: Tomado de Astorga (2013).

Figura 3. Claudia cuelga un pin a su madre y esta lo rechaza.

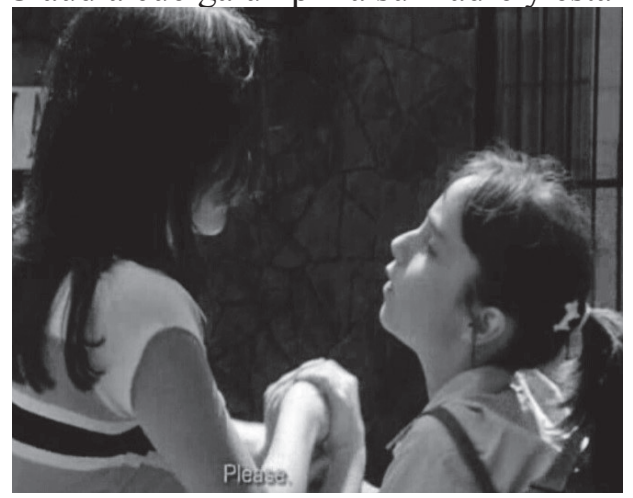

Fuente: Tomado de Astorga (2013).

Además de las evidentes prácticas escenificadas sobre el apoyo logístico a la revolución sandinista, se pueden identificar claras escenas que establecen paralelismos entre la teoría marxista y las acciones de los personajes articulados a este 
primer discurso en análisis. El más evidente de estos paralelismos lo constituye la escena en la que Claudia, al estar en la casa de su tía en Costa Rica, decide entrar en la propiedad de al lado y lanzarse a la piscina a pesar de la prohibición expresa por parte de su tía, quien le advierte vehementemente "Claudia vuelva acá, esa es propiedad privada" (ver Figura 4). Dicha acción emprendida por Claudia representa toda una reivindicación de la idea de la "abolición de la propiedad privada" y del "colectivismo" presentes en las tesis marxistas (Giner, 1987). En este sentido, en una sociedad comunista, en la que los medios de producción y la tierra se socializan y la propiedad privada no existe: Claudia no tendría razón para restringirse de lanzarse a la piscina; por lo que justo en el momento del salto se marca claramente una negativa al orden establecido en Costa Rica (respeto visceral por los bienes como ajenos e individuales). La escena siguiente muestra como Claudia es castigada por su comportamiento la que la lleva a decir: "Quiero ir a mi casa... en Nicaragua".

Figura 4. La tía de Claudia prohíbe a Claudia inmiscuirse en la propiedad

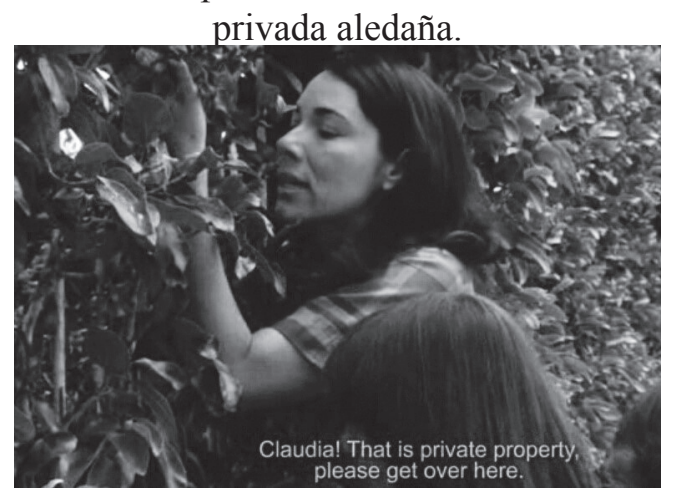

Fuente: Tomado de Astorga (2013).

Existen otras escenas donde se representa el ateísmo de las niñas: estas no saben rezar y están sustraídas de la cultura católica costarricense. Dichas escenas en particular validan la "teoría de la ideología" marxista que establece que todo sistema religioso es una "falsa conciencia" que sirve para legitimar un orden social determinado de desigualdad, permitiéndole a las clases dominantes ejercer y mantener su poder (Giner, 1987). Esto a la vez muestra la tesis del "ateísmo de Estado" prevaleciente en la URSS que no da cabida a ningún culto religioso para desplegar sus prácticas ceremoniales, ya que únicamente la teoría marxista es aquella que puede entender "científicamente" la realidad de los pueblos para modificarla (Giner, 1987).

Se pueden enumerar una serie de objetos simbólicos y prácticas de sentido que articuladas conforman el primer discurso. Con respecto a los objetos simbólicos se 
pueden citar además de los pines soviéticos: a) El color rojo del vestido de Claudia (representación de la zarina o princesa roja que quería ser; clara reminiscencia de la cultura ruso-soviética); b) las balas con las que juega Antonia y la ropa cuasi-miliar de Felipe y sus camaradas de operaciones (representa el carácter bélico que puede alcanzar la causa sandinista); c) la propaganda con imágenes del Ché Guevara, la bandera comunista en la casa en que se aloja la familia en Costa Rica (representa el comunismo y el movimiento de izquierda latinoamericana); d) la televisión con noticias del financiamiento estadounidense a la "Contra" (representa la atención puesta sobre el "enemigo"), e) la radio que reporta heridos y muertos sandinistas en el conflicto (representa la camaradería con otros militantes sandinistas; los sentidos compartidos, la amistad); f) las proyecciones de cuentos rusos sobre "pioneros" (muestra la cultura ruso-soviética).

Ahora bien, de acuerdo con las prácticas de sentido representadas se pueden mencionar: a) las historias rusas contadas en el filme (legitiman la pertenencia a la organización comunista-soviética), b) la anécdota de la visita al campamento en Cuba (anima la idea de que el único país latinoamericano exitosamente alineado y consolidado dentro orbe socialista, es un lugar emocionante de visitar); c) las danzas rusas perpetradas por las niñas y demás cánticos soviéticos (legitiman mediante el placer visual y sonoro la cultura ruso-soviética; ver Figura 5); d) la planificación de operaciones encubiertas y clandestinas por parte de Felipe y sus camaradas en las casas que funcionaban como centros de decisiones (ratifica la importancia de la causa que se sigue); e) la elaboración de pasaportes falsos, el cambio de identidad, el secretismo y el ocultamiento del asentamiento de Felipe (ratifica el carácter vulnerable de la ideología y la praxis seguida por los personajes), entre otras ya mencionadas.

Figura 5. Claudia y Antonia bailan con sus primas al escuchar la danza folclórica rusa "Kalinka".

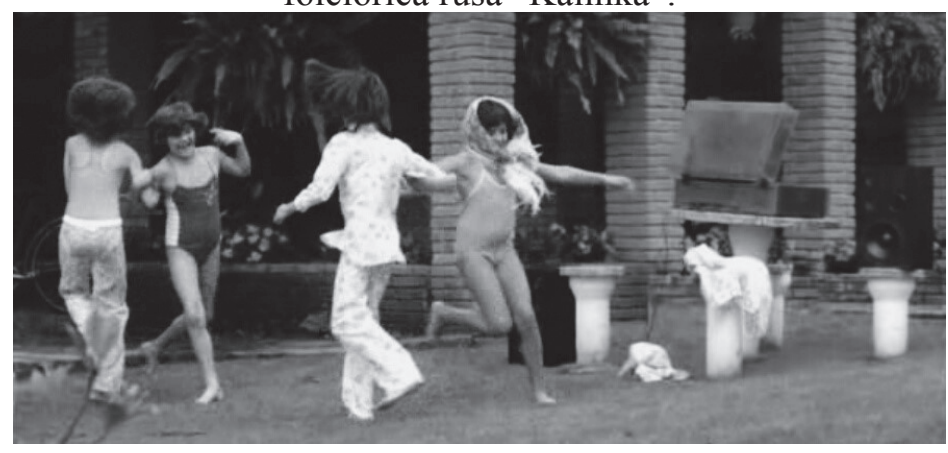

Fuente: Tomado de Astorga (2013). 


\section{El discurso dominante o hegemónico}

El segundo discurso, que se perfila como hegemónico, refleja un fuerte compromiso con la identidad costarricense y sus valores (paz, trabajo, seguridad); además que tiene perfilada la idea del "sueño americano". La familia representada, aunque tiene fuertes vínculos con el FSNL, es costarricense y está bajo el influjo de una serie de patrones culturales por el hecho de serlo; que en el caso de Magda llegan a calar a tal punto que le desvincula del primer discurso, rompe con este y lleva a la práctica una serie de actividades con un raigambre fuertemente asociado a la cultura costarricense (p.ej. huir del conflicto debido a una cultura de paz, mejorar las condiciones materiales por medio del trabajo, no exponer a los niños a la violencia, no involucrarse en actividades ilegales, entre otras cosas). Este discurso se articula en torno al significante "Estados Unidos"; es decir, Magda (quien representa por excelencia este discurso) a pesar de que nunca menciona en nombre de qué causa es que actúa como actúa, los demás personajes auguran que el objetivo de Magda y lo que genera sentido de los movimientos que realiza en el film yace en el significante "Estados Unidos", como aquel país de oportunidades y mejoramiento de las condiciones materiales de la familia.

Los sujetos que se ven anclados en este discurso son las hermanas de Magda y esencialmente Magda (el "nosotros"), quien al ser crítica de la situación en que vive y queriendo mejorar sus condiciones de vida (de ella y de las niñas), reivindica la posibilidad de vivir y trabajar en Estados Unidos como lugar de escape, aunque ello le cueste vender información privilegiada de las operaciones clandestinas de su esposo en las que ella colaboraba. El "ellos" es identificado como el "nosotros" del primer discurso: son Felipe y sus camaradas los que impiden la estabilidad laboral de Magda, su aceptación familiar, los bienes materiales requeridos y que se encuentre exenta de peligros, debido al grado de complicidad entre este personaje y el "ellos".

El proceso que vive Magda denota una desarticulación discursiva en la cual objetos -como los pines comunistas- dejan de tener sentido. A su vez, ella empieza a asumir nuevas prácticas de sentido, entre ellas se involucra con personas ligadas a la "Contra" y dibuja la estrategia para viajar a EE.UU. con sus hijas. Así, su estrategia (solución) para lidiar con la problemática (estar involucrada con el FSLN en el conflicto) consiste en salir del país por seguridad familiar, aunque ello implique vender información sobre las operaciones del FSLN en Costa Rica y fracturar el binomio amoroso. El apoyo de su hermana, quien tenía una posición estratégica en el Aeropuerto Juan Santamaría es fundamental, así como el apoyo de su familia en general, que propicia la salida de las niñas y la construcción de identidades falsas para salir del país hacia Estados Unidos. En este sentido la subjetividad política de la familia de Magda valida el discurso "colaboracionista" con la "Contra" de escape y fricción conflictiva. 
Al tener el filme una desarticulación discursiva se puede notar como las prácticas y objetos simbólicos ligados a un sujeto (Magda) dejan de generar sentido común y aparecen otras para reemplazarlas.

Este discurso tiene varios objetos simbólicos asociados, se pueden enumerar los siguientes: a) el vestido, el labial y los tacones de Magda (representan un cambio en la imagen de Magda, lo cual denota otra forma de proyectarse al mundo donde es la visibilidad y no la clandestinidad la que cuenta); b) la lavadora (viene a representar en el film el determinado objeto material que carece de utilidad práctica, ya que está desfasado y plantea un símil con la relación de pareja y su fe en los planes de su esposo); c) la casa de la hermana de Magda (representa el orden y plantea la idea de estabilidad y felicidad familiar). Este discurso está desprovisto de gran cantidad de objetos simbólicos que hacen sintomática la articulación de un nuevo discurso, así también lo está de prácticas de sentido.

Sin embargo, las siguientes prácticas o acciones representadas logran establecer que Magda encarna al costarricense pacífico (exento de violencia), democrático (que elige como vivir su vida) y trabajador (que de una manera legal y estable logra sacar a su familia adelantes): a) la visita de Magda al representante estadounidense (colaborador de la "Contra") a escondidas de su esposo con quien tuvo un acuerdo, donde entraña la traición como estrategia para lograr su cometido; b) planea junto con su hermana una forma de salir de Costa Rica (por ende del conflicto) y lograr establecerse en EE.UU.; c) abandonar a Claudia, a quien claramente observa como un peligro para su pronóstico de seguridad familiar y nueva vida estable; d) rechaza el pin comunista que le cuelga Claudia (representa el punto culminante de la desarticulación de la lógica pro-sandinista). 
Figura 6. Claudia se cubre bajo el pupitre tras el sonido del timbre escolar. Esta imagen revela el conflicto latente en Nicaragua mediante el cual todo sonido que emula una alarma implica peligro.

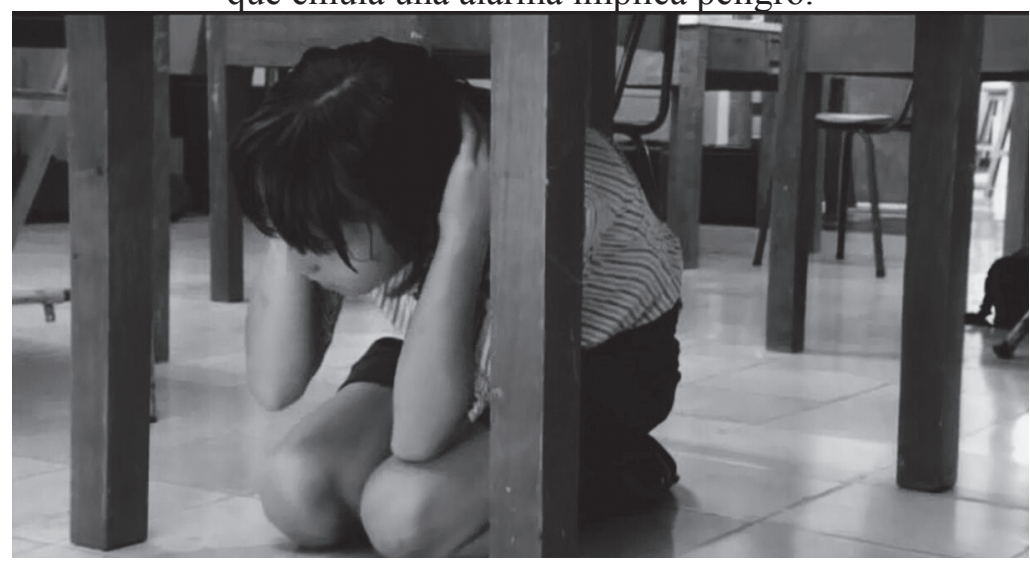

Fuente: Tomado de Astorga (2013).

El diálogo siguiente refleja la desarticulación o dislocación referida en una escena donde Claudia entiende la traición de su madre (al saber que estuvo en Miami durante su desaparición), donde refleja estrictamente que el referente discursivo en el film yace en cuál país sirve de ideal donde vivir:

(Las niñas en la escuela hablan en su receso).

Amiga 1 - “¿Dónde está su mamá?”.

Amiga 2 - "Naty, ¿sus papás están separados?".

Amiga 1 - “Qué fue lo que pasó? ¿Lo traicionó con otro hombre?”.

Claudia - "No. Con otro país".

Entonces bien, ¿cuál lógica impera en el antagonismo escenificado según la Teoría del Discurso? Desde el punto de vista de los sujetos, el antagonismo dibuja y articula dos bandos contrapuestos: por un lado se tiene a Magda y su familia que actúa de acuerdo con la hegemonía cultural costarricense, reflejando el ideal pacífico, no confrontativo, democrático y laborioso al huir del conflicto (problemática sufrida); mientras que por otro, se tiene al bando de quienes defienden la causa sandinista y la cultura ruso-soviética (Felipe, Claudia y los camaradas nicaragüenses), por la que continuarían en el conflicto hasta que se defina un vencedor. Por ello, la lógica imperante es la lógica de la equivalencia que denota un antagonismo entre un "nosotros" y un "ellos", cuya disputa cultural trasgrede una relación de pareja y desintegra una familia como resultado. 


\section{Reflexiones finales}

Las representaciones políticas no solamente tienen cabida a través de la televisión, los periódicos y la radio: el cine -y más recientemente las series de televisión o de internet-como un mass-media vigente en el s. XXI, también posee una importante cuota de propagación de opiniones, visiones de mundo, mitos e imaginarios. La presentación estética y discursiva de un producto audiovisual posee potencial para legitimar una serie de actores, prácticas, estrategias y símbolos políticos que, articulados en determinadas lógicas narrativas, pueden replicarse, discutirse o rechazarse en sociedades democráticas y con libertad de expresión. Es por ello que el cine y los contenidos proyectados a través de él, merecen tener su cuota de espacio en las agendas investigativas y pedagógicas dentro de la Ciencia Política. Una estrategia de entrada puede plantearse a través del concepto de soft power, entendido como un instrumento de poder, en mayor medida geopolítico, que no funciona a través del clásico recurso de la violencia sino con la capacidad de modelar las preferencias de otras naciones, o bien como un "dispositivo de violencia simbólica" al que se le "asigna la tarea de cultivar el deseo de un orden planetario estructurado conforme a los valores del global democratic marketplace" (Mattelart y Neveu, 2004, p. 160).

En suma, Princesas rojas contextualiza el caos antagónico del conflicto bélico nicaragüense que se interioriza en la vida familiar de costarricenses colaboradores con la "defensa de la revolución" en Nicaragua, provocando una dislocación entre los integrantes de la familia. Entran en pugna dos visiones político-culturales distintas que separa las orientaciones familiares: por un lado hay un modelo de familia combativa, sacrificada y que asume una serie de riesgos intentando recuperar la Nicaragua sandinista (para expandir el comunismo en Costa Rica: potenciar los "movimientos pioneros" o las organizaciones juveniles comunistas), y por otro lado hay un modelo de familia pacífica, segura y próspera exenta de los riesgos que suscita el conflicto nicaragüense (huir a EE.UU.). El antagonismo parte de un diagnóstico compartido por los personajes que escenifican la disputa: el peligro que genera el conflicto para la supervivencia familiar; sin embargo, los personajes dentro de cada discurso gestionan dicha problemática de forma distinta: o continúan apoyando un bando en el conflicto o huyen.

El caso analizado revela cómo desde esta película costarricense se ha representado la disputa y la confrontación de ideas como esencia misma de la política. Se observa como los grandes conflictos bélicos pueden llegar suponer para una familia costarricense que colaboró con el sandinismo en los ochenta, desde dilemas culturales complejos hasta diferencias en torno a las formas de vivir teniendo un conflicto armado que termina por ser interiorizado. Además, presenta una escenificación clara de un discurso dominante que problematiza la identidad del costarricense mismo ante un evento o acontecer histórico que realmente sucedió 
(conflicto bélico nicaragüense) y que permite revisitar o rememorar la historia de una forma alterna al imaginario sedimentado: esto es, ahondando en el hecho de Costa Rica funcionó como escenario de retaguardia durante la guerra centroamericana y que costarricenses participaron de manera activa tanto en la Revolución Sandinista como en la posterior guerra civil nicaragüense ${ }^{15}$.

\section{Referencias}

Cortés, M. L. (2011). El nuevo cine costarricense. Revista Comunicación, 20, 4-17.

Cortés, M.L. (2016). Fabulaciones del nuevo cine costarricense. San José: URUK Editores.

Giner, S. (1997). Historia del pensamiento social. Barcelona: Editorial Ariel.

González, I. (2012). Un asalto al discurso histórico. La práctica escritural de Tatiana Lobo. Revista de Filología y Lingüística, 38, 35-45.

Huezo Mixco, M. (2017). La casa de Moravia. México: Alfaguara.

Iglesias, P. (2010a). Cine y memoria histórica. Katyn de Andrzej Wajda y nuestra guerra civil. Viento Sur. Disponible en: http://www.vientosur.info/documentos/Pablo.pdf (Acceso: 5/04/2017).

Iglesias, P. (2010b). Cine y Geopolítica. Geopolítica(s), 2, 337-340.

Iglesias, P. (2013). Maquiavelo frente a la pantalla. Cine y politica. Madrid: Akal.

Laclau, E. y Mouffe, C. (1987). Hegemonía y estrategia socialista. Hacia una radicalización de la democracia. Madrid: Siglo XXI.

Madriz, G. y Sáenz, R. (2016). Realidades políticas mediadas: el imaginario social de la democracia en el cine costarricense, Estudios, 33, 1-23.

Mattelart, A. y Neveu, E. (2004). Introducción a los estudios culturales. Barcelona: Ediciones Paidós.

Mouffe, C. (2011). En torno a lo político. Buenos Aires: Fondo de Cultura Económica.

Nikiforov, A. (2017). Historical memory: the construction of consciousness. Russian Social Science Review, 58, 379-391.

15 La literatura regional y costarricense aventaja, por lejos, al cine en este aspecto. La publicación de la novela La casa de Moravia (2017), del escritor salvadoreño Miguel Huezo Mixco, es de especial interés ya que pone sobre la palestra esta cuestión; desarrollando la participación de costarricenses en la retaguardia de la guerra civil salvadoreña, por una parte, y revisitando, por otra, un punto negro dentro de la historia oficial del país: el asesinato de Viviana Gallardo. 
Pacheco, D. (2013). La identidad costarricense ante los dilemas de la migración, diversidad cultural y desigualdad socioeconómica. Reflexiones, 92, 23-33.

Rancière, J. (2001). La fábula cinematográfica. Barcelona: Paidós.

Rancière, J. (2011). El malestar en la estética. Buenos Aires: Capital Intelectual.

Sánchez, A. (2011). Cachaza va a la guerra: la locura y la pesadilla de la Guerra Civil de 1948. En J. Chen Sham (ed.), Complejidad polifónica y dialogismo: la narrativa de Virgilio Mora. (19-34). San José: Editorial Fundación Interartes.

Von Beyme, K. (2014). On political culture, cultural policy, arts and politics. New York: Springer.

Zamora, A. (1996). El conflicto Estados Unidos-Nicaragua 1979-1990. Managua: Fondo Editorial CIRA.

\section{Filmografía citada}

Astorga, L. (Dirección). (2013). Princesas rojas [Película]. Costa Rica y Venezuela: Hol y Asociados / La Feria Producciones / Suécinema.

Castillo, O. (Dirección). (2011). El compromiso [Película]. Costa Rica y Argentina: OC Producciones / Orsay Troupe.

Ferraz, V. y Martínez, I. (Dirección). (2010). El último comandante [Película]. Brasil y Costa Rica: Tres Mundos Producciones.

Yasin, I. (Dirección). (2008). El camino [Película]. Costa Rica: Producciones Astarte / DART/Cinequanon / Gedeon Programmes. 